\begin{tabular}{c|c|c}
\hline \hline Vol. 60: $77-84,2004$ & DISEASES OF AQUATIC ORGANISMS \\
Dis Aquat Org & Published July 5 \\
\hline
\end{tabular}

\title{
'Cup cell disease' in the colonial tunicate Botryllus schlosseri
}

\author{
Elisabeth Moiseeva, Claudette Rabinowitz, Irena Yankelevich, Baruch Rinkevich*
}

National Institute of Oceanography, Tel Shikmona, PO Box 8030, Haifa 31080, Israel

\begin{abstract}
A new progressive, fatal disease called 'cup cell disease' was characterized in ex situ cultures of Botryllus schlosseri, a colonial tunicate. The disease originated as a few dark spots growing within zooids. The infected colonies then started to deteriorate, morphologically diagnosed by ampullar retraction, lethargic blood circulation and by a swollen and soft tunic matrix. In later stages of the disease, developed buds were also affected. Many large black dots were scattered within the tunic matrix, and zooids were transformed to opaque, dilated, sac-like structures, signaling impending death. Colonies were infected periodically, even without direct tissue contact. The time course from first appearance to colony death ranged between 30 and $45 \mathrm{~d}$. Histological studies, in vitro culturing of blood cells and blood smears revealed the existence of numerous cup-like cells (up to $4.8 \mu \mathrm{m}$ diameter on average) with a yellowish cell wall and transparent cytoplasm that was not stained by various dyes (except azocarmine-G). Cells were refractive under bright-field illumination and revealed a flattened wall with flanges, characteristic of species of the phylum Haplosporidia. Cup cells aggregated in blood vessels and in internal parts of zooids and buds and were phagocytosed by blood cells. In a single case, plasmodia-like structures were found only in the tunic matrix of an infected colony. This is the first record in botryllid ascidians of an infectious lethal disease associated with haplosporidian protists.
\end{abstract}

KEY WORDS: Ascidians $\cdot$ Botryllus $\cdot$ Disease $\cdot$ Haplosporidia $\cdot$ Mariculture

\section{INTRODUCTION}

The colonial tunicate Botryllus schlosseri (Chordata: Ascidiacea), a cosmopolitan inhabitant of shallowwater substrata, has become increasingly important as a model experimental species for various biological disciplines, including immunology, physiology, ecology, genetics, developmental biology, aging (Boyd et al. 1986, Magor et al. 1999, Rinkevich 2002) and more. During the last 2 decades, several studies (Boyd et al. 1986, 1990, Kawamura \& Nakauchi 1986, Rinkevich \& Shapira 1998) have dealt specifically with ex situ culturing of botryllid ascidians, to ensure year-round availability of colonies or the establishment of defined genetic stocks.

Botryllus spp. colonies encrust the substrate and are attached in nature to rocks, algae, other organ- isms, floats, ship bottoms, and a variety of shallowwater artificial objects. Each colony bears up to several hundreds of morphologically identical units (zooids) embedded within a gelatinous matrix, the tunic. All zooids in a single colony are connected to each other through a ramifying network of blood vessels, which, in the periphery of the colony, bear sausage-like blind enlargements (vascular ampullae). All zooids of a single colony are of identical genetic constitution formed by blastogenesis, a complex and highly synchronized phenomenon of weekly cyclic asexual budding. When a colony is split in nature or by experimental procedures into 2 or more fragments, each subclone usually continues to grow independently to form a new large isolated colony. This enables simultaneous study on different subclones of the same genotype. 
Using the laboratory facilities at Haifa, we maintain and culture Botryllus schlosseri colonies first established in 1988. The culture conditions, which have improved with time (Rinkevich \& Shapira 1998), maintain the tunicates in good condition (i.e. fast growth rate), and support sexual reproduction, high survivorship of young individuals and long-term maintenance under laboratory conditions. However, occasionally, the entire stock of colonies growing in one of the culturing tanks (17 l standing-seawater tanks; Rinkevich \& Shapira 1998) or the entire set of colonies growing in the culture room $\left(20^{\circ} \mathrm{C}\right)$ dies simultaneously without the emergence of any known agent. Diseases causing mortality to urochordates have rarely been reported (Monniot 1990). Herein, we describe 'cup cell disease' in cultured Botryllus schlosseri colonies that is associated with the appearance of a haplosporidian protist. Infected colonies characteristically exhibited swollen zooids with dark pigmentation that gradually deteriorated and died.

\section{MATERIALS AND METHODS}

Animal maintenance. Botryllus schlosseri colonies (originating from Monterey, Half Moon Bay and Moss Landing, Marinas, California, USA, and from the Istra Peninsula, Croatia) were kept in the laboratory at Haifa in $17 \mathrm{l}$ standing-seawater, glass tanks (up to 20 colonies per tank) as described earlier (Rinkevich \& Shapira 1998). Colonies were attached to $5.0 \times 7.5 \mathrm{~cm}$ glass slides, 1 colony per slide, suspended vertically in slots of glass staining racks. Seawater (from the Mediterranean) was changed twice weekly. The colonies were fed once daily as described earlier (Rinkevich \& Shapira 1998) and subjected to a 12:12 h light:dark regimen. The water in each tank was aerated by bubbles from an air stone and maintained at $20^{\circ} \mathrm{C}$ in a temperature-controlled culture room. Colonies were cleaned weekly with a small soft brush to remove debris and fouling organisms.

Histological preparations. Healthy and diseased Botryllus schlosseri colonies growing on glass slides were fixed in either Bouin's fluid, $4 \%$ solution of buffered formalin, or Carnoy's fixative for 40 to $60 \mathrm{~min}$. After fixation, the colonies were separated from the substrate, dehydrated in ethyl alcohol, and embedded in paraplast. Sections of 4 to $5 \mu \mathrm{m}$ thickness were prepared by rotation microtome (Jung Multicut, Leica). Sections were stained with alum hematoxylin and eosin, Heidenhain's azan, alcian blue (pH 3.0) in combination with azocarmine-G or periodic acid-Schiff's reagent (PAS-method) and counterstained with hematoxylin. Sections were observed under bright-field illumination.
In vitro culture of blood cells. Diseased colonies were rinsed several times with artificial seawater (ASW; Stock Solution 2 in Rinkevich \& Rabinowitz 1993; pH 7.3, 1200 mOsm), peeled off the glass slides by sterile, 1-edged surgical carbon-steel razor blades (No. 1; VWR) and transferred to Petri dishes $(10 \mathrm{~cm})$ containing ASW. Each Botryllus schlosseri colony was treated separately. The tunic matrix and the zooids were then teased apart by a pair of fine stainless steel forceps; exuded blood was allowed to accumulate in the ASW. Pieces of tissue and tunic were removed, cell suspensions were filtered through a $40 \mu \mathrm{m}$ poresized nylon cell strainer (Falcon, Becton Dickinson Labware) and gently centrifuged $\left(400 \times g, 4^{\circ} \mathrm{C}, 10 \mathrm{~min}\right)$. The pellet was resuspended in a large volume of ASW and re-centrifuged $(\times 5)$. In the final rinse, cells were resuspended in tunicate culture medium (TCM; Rinkevich \& Rabinowitz 1993). All the above protocols were carried out on ice and with ice-cold medium. Most of the harvested cells were bloodborne cell types, although small fragments of zooidal tissue were found. Collected cells were cultured in 24-well plastic plates (TPP), in a humidified $\mathrm{CO}_{2}$ incubator $\left(19^{\circ} \mathrm{C}\right)$. All observations were performed with an Olympus inverted phase-contrast microscope. Smears (on glass slides) were also prepared from the collected cells, fixed in 100\% methanol and stained with $0.1 \%$ erythrosine.

In vitro culture of buds and zooids. A blastogenic Stage ' $C$ ' colony (sensu Mukai \& Watanabe 1976) at an initial stage of cup cell infection was used for the isolation of primary buds and zooids. The colony, growing on a glass slide, was cleaned with a soft brush, briefly immersed in $70 \%$ ethanol and submerged in filtered seawater (FSW; $0.2 \mu \mathrm{m}$ ) with $50 \mu \mathrm{m}$ $\mathrm{ml}^{-1}$ gentamycin. Healthy-seeming buds $(\mathrm{n}=80)$ and zooids $(\mathrm{n}=16)$ were carefully extirpated by sterile, pyrogen-free syringe equipped with $28 \mathrm{G}$ needles and immersed in ambient medium under a dissecting stereomicroscope (Olympus). The tunic coating was removed and the buds and zooids were gently detached from the rest of the colony. Explants were collected with a sterile $100 \mu \mathrm{m}$ pore-size nylon cell strainer and thoroughly rinsed with FSW. A small number of explants (3 to 6) were cultured per well (zooids and buds in separate wells) in 24-well TPP plates using Fischer's synthetic liquid medium and $3 \%$ heat-inactivated fetal calf serum (nutrient supplement). Osmolarity was adjusted to seawater level with the addition of double-strength ASW. A final volume of $500 \mu \mathrm{m}$ well $^{-1}$ was added and partially replaced with fresh medium once every $2 \mathrm{wk}$. All media and media supplements were purchased from Biological Industries. All other chemicals were purchased from Sigma. 


\section{RESULTS}

\section{Etiology}

At the onset of the disease, Botryllus schlosseri colonies looked normal, with their regular arrangement of zooids in star-shaped systems and with uninterrupted blastogenic cycles. The earliest recognizable morphological feature of the disease was the appearance of 1 or a few dark spots of various form and size (Fig. 1a) within the zooids. These dark spots resembled some of the senescence phenomena in old colonies, in which black dots appear during incomplete blastogenic cycles (Lauzon et al. 2000) or when incomplete allogeneic resorption has occurred (Rinkevich \& Weissman 1987). With time, more and more dark-pigmented dots appeared. Finally, with intense pigmentation, the infected colonies started to deteriorate (Fig. 1b-d). Peripheral ampullae began to retract from the outer tunic layer, blood circulation became progressively lethargic, and the tunic matrix became softer and swollen. During the next few days, systemic blood became static in parts of the infected colonies; the developed buds were also affected, and gradually separated from parental zooids, indicating arrested development. Zooids were then transformed to opaque dilated sac-like structures (Fig. 1d), resulting in disorganized colonial morphology (Fig. 1b-d). In these swollen zooids, the hearts were characterized by weak and infrequent pulsations and the soma had more intense pigmentation, signaling impending death (as indicated by non-random senescence, Lauzon et al. 2000). During the later stages of the disease, many black dots ( $0.5 \mathrm{~mm}$ to system size) were scattered throughout the colony matrix, sometimes forming small patches of several dots each (Fig. 1b, d). The disease usually lasted 30 to $45 \mathrm{~d}$ from the onset of the morphological appearance, 'moving' from the first infected zooid to all zooids and systems of the colony. In the final phase, all zooids in the infected colonies were dead, as indicated by lack of a heartbeat. The dying colonies decayed within the next 1 to $2 \mathrm{~d}$. During this period, we histologically analyzed (see next subsection)
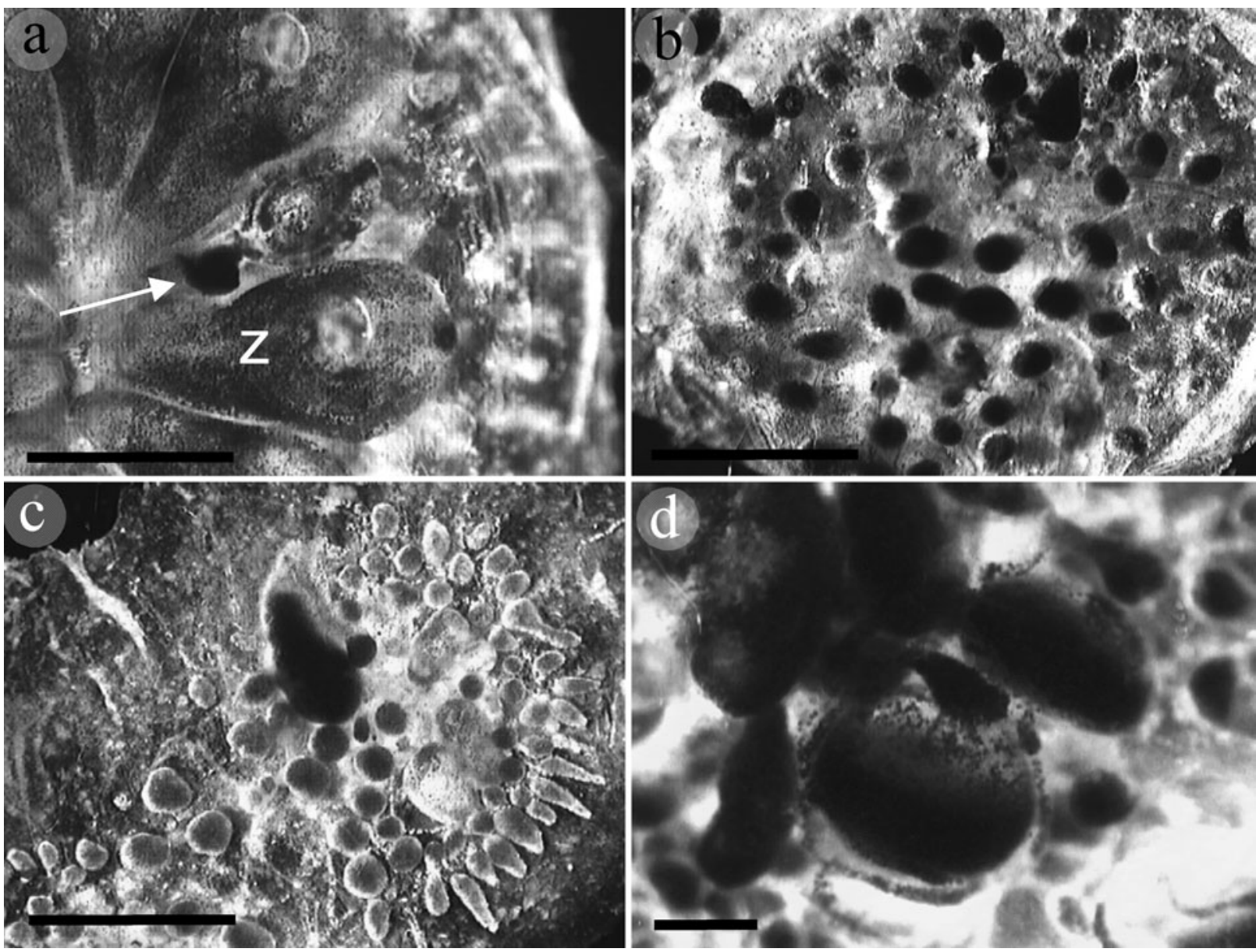

Fig. 1. Botryllus schlosseri. 'Cup cell disease' in colonies. (a) Onset of disease as dark spot within a zooid (z) (arrow); (b-d) later stages of infected colonies with disorganized colonial morphology. z-functional zooid. Scale bars: $(\mathrm{a}, \mathrm{b})=1000 \mu \mathrm{m}$; $(\mathrm{c}, \mathrm{d})=500 \mu \mathrm{m}$ 
30 suspected subclones of infected colonies. Cup cell disease was identified in $22(73.3 \%)$ cases. The other 8 diseased colonies, although morphologically presenting a similar syndrome of black dots, lacked the characteristic cup cells.

Cup cell disease caused serious epidemics in the cultures and spread within the same aquarium from 1 Botryllus schlosseri colony to another, even without direct tissue-to-tissue contact (data not shown). We could rescue infected colonies if, at an early stage, the dark spot-bearing areas together with the neighboring zooids/systems were surgically removed. The disease was endemic in our cultures, appearing periodically during the course of this study (November 2000 to October 2002).

\section{Histology}

Histological observations with the light microscope of colonies at the onset of disease (Fig. 2a) revealed a typical syndrome for this disease, the expansion of blood vessels in the dark-pigmented area. The dark spots typically resided within ampullae-like dilated lacunae. Of special interest was the observation that blood vessels of the infected colonies were systematically loaded with foreign cell-like structures, which, in accordance to their morphology, will here be termed 'cup cells' (Fig. 2b-d). Cup cells in the histological sections were characterized by a yellowish cell wall and transparent cytoplasm which was not stained by hematoxylin and eosin, aniline blue, Orange $\mathrm{G}$, alcian blue or Schiff's, reagent, but was positively stained an intense red color by azocarmine-G. Under bright-field illumination, the cup cell cytoplasm was highly refractive. Nuclei were usually situated at the bottom of the cell and (although sometimes in the center of the cell), stained lightly with PAS and eosin.

Cup cells were a variety of sizes; the largest (4.8 \pm $0.26 \times 4.2 \pm 0.18 \mu \mathrm{m} ; \mathrm{n}=12$ ) was not abundant and the most common size averaged $3.7 \pm 0.14 \times 3.4 \pm 0.12 \mu \mathrm{m}$ $(\mathrm{n}=25)$. In some of the histological sections, cup cells had a pyriform shape with 2 short filaments originating at the narrow end of the cell (see below). Most of the cup cells were located in the newly formed vascular dilations (Fig. 2a,c,d). Cup cells were also observed inside phagocytes (Fig. 2e,f). Many cells resided within the lumen of blood vessels in the branchial sac region and single cup cells (no aggregates) were also seen within the tunic matrix and in the blood sinuses around the developing buds.

Compared with healthy colonies, cup cell aggregations were associated with increased numbers of granular and hyaline leucocytes. In progressive stages of the disease (Figs. 1b-d \& 3a,b), the whole body-plan construction of visceral tissues, epithelia (peribranchial epithelium and epidermis), branchial baskets and other organs in both buds and zooids exhibited degenerative changes indicative of impending death. Some organs (such as buds; Fig. 3c) were still confined by an intact epithelium that was degraded in later stages. The entire tunic matrix then possessed dilated lacunae that were congested with cup cells (Figs. 2c,d \& $3 a, b, d)$, and with small remnants of distorted zooid organs and enlarged macrophages $(19.6 \pm 1.2 \mu \mathrm{m}$ [ $\mathrm{n}=10]$ compared with $13.5 \pm 0.5 \mu \mathrm{m}[\mathrm{n}=10]$ in healthy colonies; Fig. 2e,f). Enlarged macrophages were present from the onset of the disease.

In 1 of the 22 infected colonies that demonstrated the cup cell disease histologically (the colony was in an advanced stage of the disease), we observed, in the tunic matrix, foreign structures (Fig. 4) that resemble the plasmodia of Haplosporidia (Ormières 1965, Perkins 1991) at the sporocyte stage. The cells (7.1 \pm 1.3 to $9.4 \pm 0.4 \mu \mathrm{m}$ in diameter; $\mathrm{n}=21$ ) were not found in the blood system (as opposed to cup cells) and each had a globular morphology comprising several small spheres, all confined in a single envelope (Fig. 4). The small spheres, such as the cup cells in the blood, were specifically stained by azocarmine-G and became highly refractive under bright illumination. However, since with light microscopy we could not observe nucleoli within the small spheres (as opposed to former studies in which plasmodia was histologically confirmed by electron microscope observations), these structures are termed plasmodia-like structures.

\section{In vitro cultures}

Cup cells were cultured in vitro for $3 \mathrm{wk}$. The cells did not attach to the plate's substrate and there were no signs of cell proliferation (which would have excluded them from the phylum Haplosporidia). Whether alive (Fig. 5a,b) or in fixed smears (Fig. 5c,d), cup cells displayed the general structures of sporoblasts and spores of the phylum Haplosporidia, including the typical flattened wall with flange (Fig. 5b-d) characteristic of the genera Minichinia and Haplosporidium (Perkins 1991). Cup cells were also seen in primary cultures from apparently healthy (no black dots) colonies, indicating that the disease may be latent in the early stages of infection.

\section{DISCUSSION}

The phylum Haplosporidia consists of parasitic protists that form spores containing only 1 sporoplasm, and a spore-type that has an orifice which, in some 

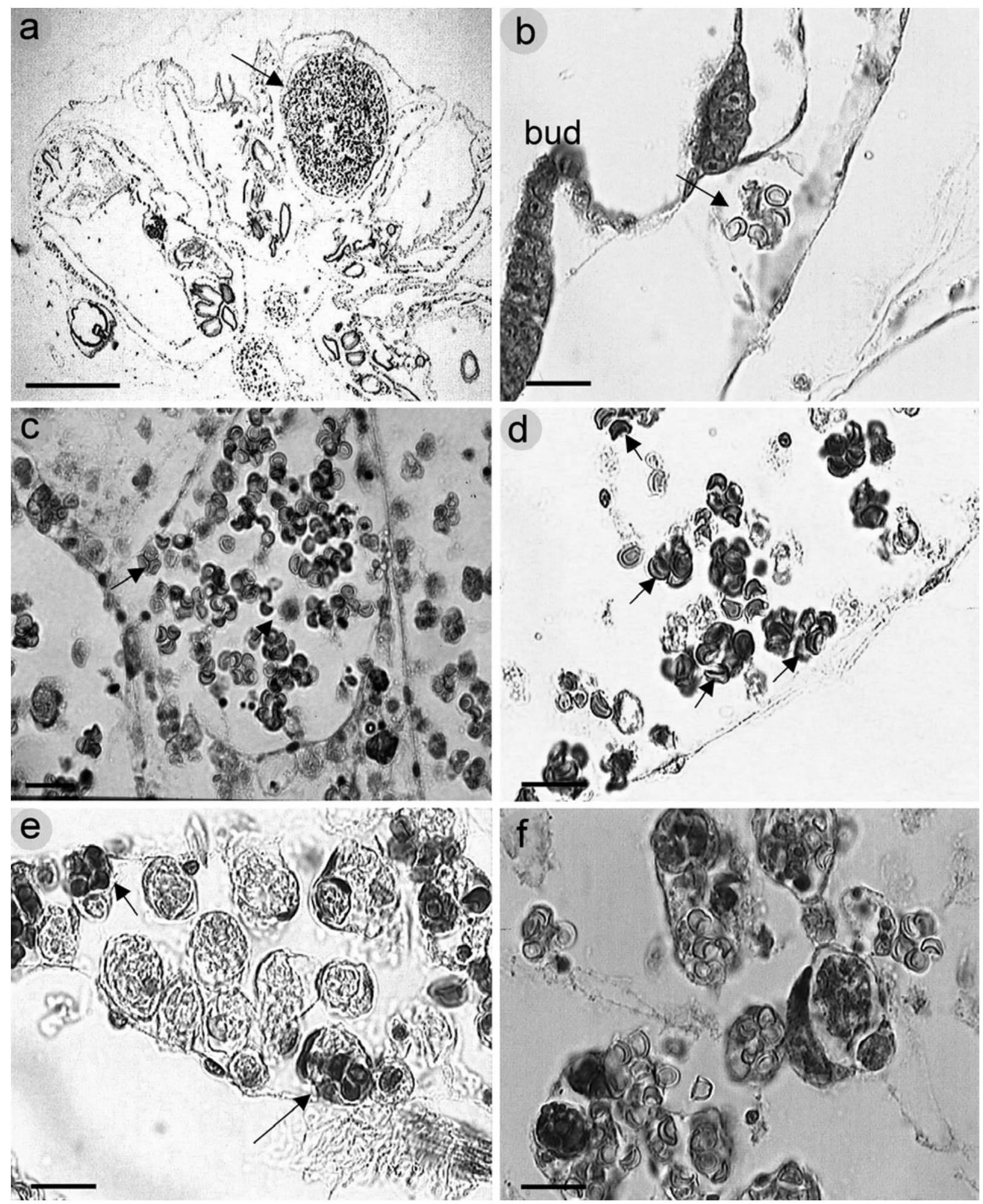

Fig. 2. Botryllus schlosseri. 'Cup cell disease' at cellular level. (a) Onset of disease with aggregates of cup cells in a zooid (arrow); Azan, $\times$ 40. (b,c) Cup cells (arrows) within vascular system (b) and ampulla (c); both alum hematoxylin and eosin, $\times 1000$. (d) Aggregates of cup cells (arrows) within vascular dilations; Azan, $\times 1000$; (e,f) Cup cells ingested by phagocytes at (e) onset of disease, with ingested cup cells within a few macrophages (arrows) and other macrophages apparently empty, and (f) later stages of the disease when most macrophages contain ingested cup cells; (e) Azan; (f) alum hematoxylin and eosin, $\times 1000$. Scale bars: 

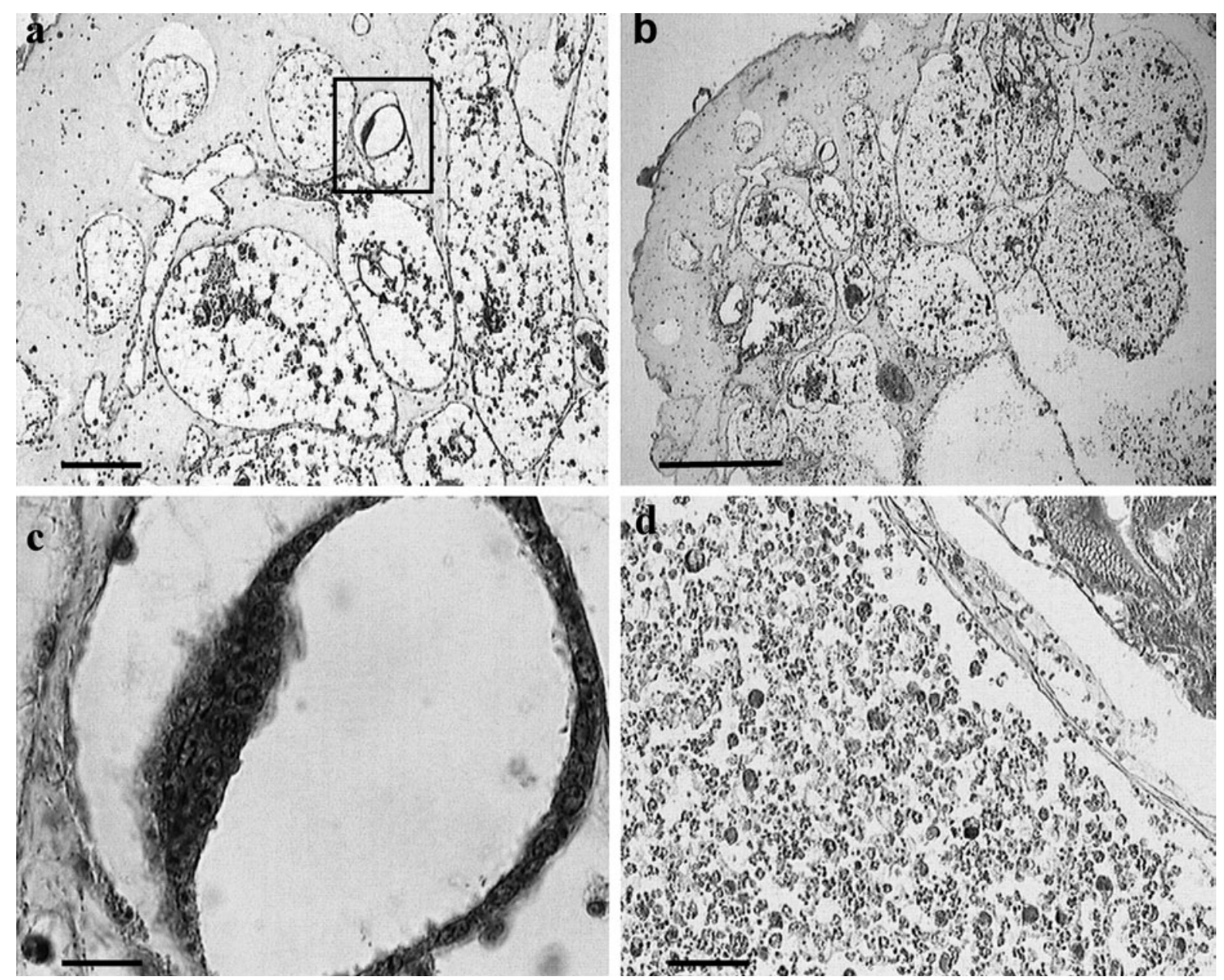

Fig. 3. Botryllus schlosseri. Histology of infected colonies in later stages of disease. (a) (b) Body plan of deteriorating tunicate; (c) portions of bud soma still intact (high magnification of outlined square in (a); both alcian blue and azocarmine-G; (d) dilated lacuna congested with cup cells. (a) $\times 100$; (b) $\times 40$; (c) $\times 1000$; (d) $\times 200$. PAS. Scale bars: (a) $=100 \mu m_{i}(b)=500 \mu m_{i}(c)=10 \mu m_{i}$ (d) $=50 \mu \mathrm{m}$
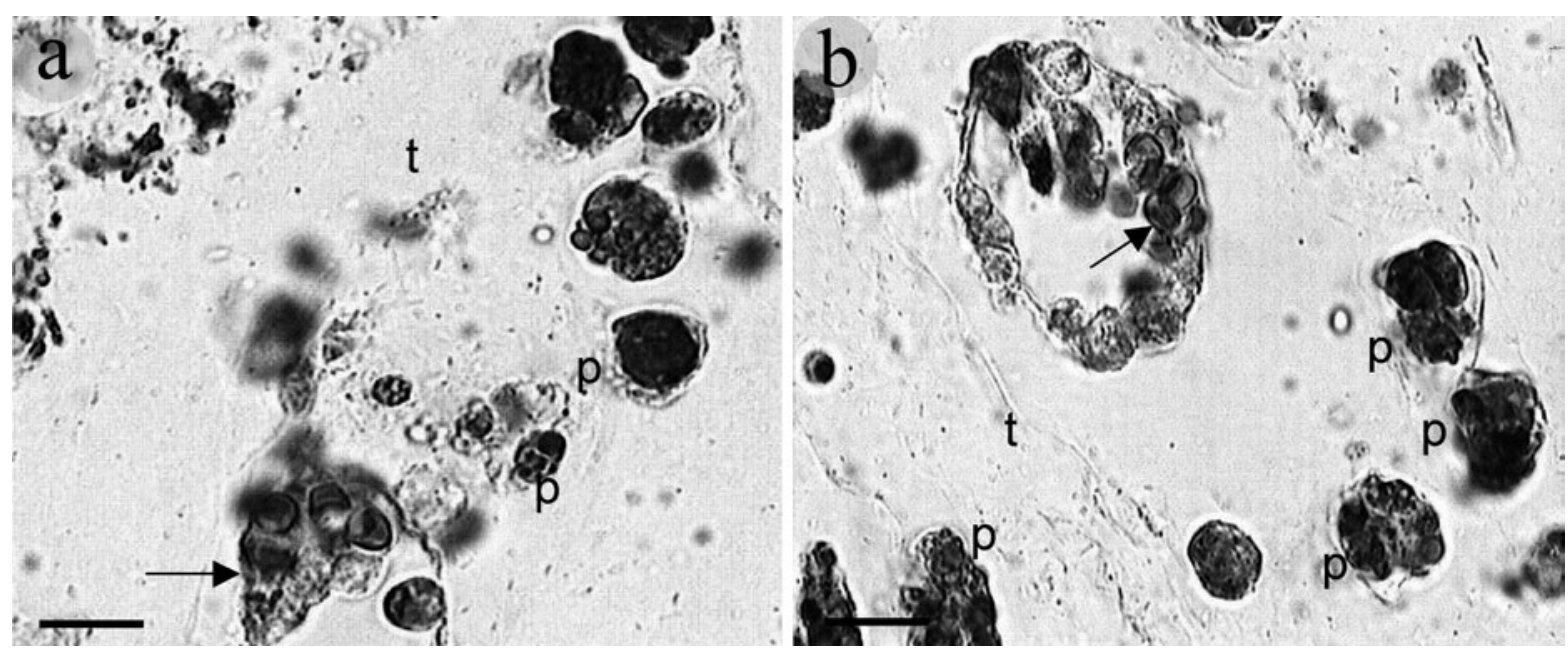

Fig. 4. Botryllus schlosseri. Plasmodia-like-structures (p) in tunic (t) matrices of diseased colonies; arrows indicate cup cells within constricted blood vessels. Azan, $\times 1000$. Scale bars: $(a, b)=10 \mu \mathrm{m}$ 

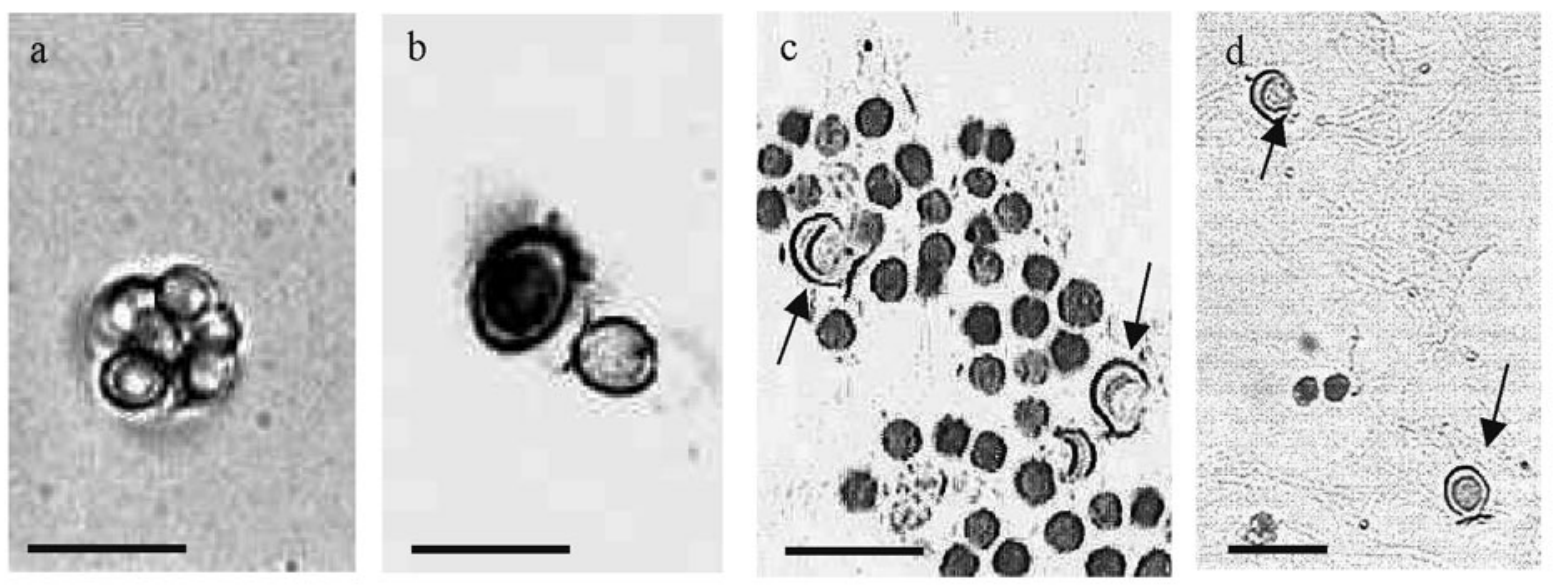

Fig. 5. Botryllus schlosseri. Cup cells $(\mathrm{a}, \mathrm{b})$ in vitro and $(\mathrm{c}, \mathrm{d})$ in fixed smears of cells (arrows); $\times 1000$. Scale bars: $(\mathrm{a}-\mathrm{d})=10 \mu \mathrm{m}$

species, is covered with a hinged operculum on the outer face of the orifice (Perkins 1991). In the tunicates, Duboscq \& Harant (1923) were the first to find a haplosporidian, which was defined as Haplosporidium ascidiarum. This haplosporidian species continuously parasitizes tunicates (Ciancio et al. 1999) and, at present, it is the only haplosporidian known from tunicate hosts. All known haplosporidians are parasites of freshwater and marine invertebrates. However, despite numerous attempts, no haplosporidian infection has been experimentally transmitted by spores or by any other cellular stage (Perkins 1991). Moreover, Haplosporidia have not been established in culture and, therefore, life cycles have not been elucidated for any species. The reservoirs of infectious cells and pathways of transmission are not known (Perkins 1990). Haplosporidian pathogens of several marine taxa (i.e. molluscs, decapod crustaceans) can kill their hosts and dramatically reduce host population densities (Perkins 1990, Figueras et al. 1996, Barber et al. 1997, Ciancio et al. 1999, Diggles et al. 2002, Hine \& Thorne 2002, and literature therein). The present study presents, for the first time, this type of phenomenon in tunicates.

Morphologically, the disease is first apparent as black-brown dots within the tunic matrix, similar to diseases documented for other infected invertebrate species (Perkins 1990, 1991).

We identified the parasitic agent in Botryllus schlosseri associated with the cup cell disease as belonging to the phylum Haplosporidia, according to its spore size and shape (especially the appearance of the flattened flange of the cell wall), the dark pigmentation of the spore aggregates, the single sporoplasm per spore, the lack of proliferation, the plasmodium and the general characteristics of disease development. Some B. schlosseri blood cells, such as macrophages and granular and hyaline leucocytes, appear to react against the parasitic forms, but without success, and only surgical elimination of infected tissues during early stages of the disease can rescue an infected colony. The parasite is transferred through seawater (it develops in new colonies without any direct contact with infected B. schlosseri colonies), repeatedly appears in our cultures, and may be a serious problem in stocks of inbred lines or other important Botryllus spp. genotypes raised for specific scientific needs. As in other tunicates (Ormières \& De Puytorac 1968, Ciancio et al. 1999), the entire life cycle of the parasite may occur in the intestinal epithelium of the host (although this has not been recorded in infected $B$. schlosseri), and ingestion can therefore be an important factor in disease transmission. However, the parasite may invade all ascidian tissues, and in heavy infections is mainly evident through the dark coloration caused by its brown spores (Ormières 1965).

Botryllus schlosseri colonies under ex situ conditions show high survivorship, and several long-term cultures have been established (Boyd et al. 1986, Rinkevich \& Shapira 1998). Cup cell disease in B. schlosseri is a progressive, degenerative process associated with the parasitic cup cells. Like other diseases with unknown enigmatic agents, it may significantly endanger years of research. B. schlosseri hosts other parasites, including the gregarine Lankesteria botrylii (Ormières 1965) and ciliates (literature in Monniot 1990), and further parasites have been found in various botryllid ascidians (Levine 1981). Infection of tunicates is probably a common phenomenon in nature. Levine (1981) examined 361 ascidian specimens of the 20 most common species from the Californian coast; of these, 14 species were parasitized at prevalence rates of 10 to $100 \%$, with rates varying according to species. Parasitic diseases should, therefore, be considered significant biological factors when culturing extensive ex situ stocks of tunicates, including botryllid ascidians. 
Acknowledgements. This study was supported by the USIsrael Binational Science Foundation, the Israel Science Foundation (456/01-1) and the NIH (No. ROI-DK54762).

\section{LITERATURE CITED}

Barber BJ, Langan R, Howell TL (1997) Haplosporidium nelsoni (MSX) epizootic in the Piscataqua River estuary (Maine, New Hampshire, U.S.A). J Parasitol 83:148-150

Boyd HC, Brown SK, Harp JA, Weissman IL (1986) Growth and sexual maturation of laboratory-cultured Monterey Botryllus schlosseri. Biol Bull 170:91-109

Boyd HC, Weissman IL, Saito Y (1990) Morphologic and genetic verifications that Monterey Botryllus and Woods Hole Botryllus are the same species. Biol Bull (Woods Hole) 178:239-250

Ciancio A, Scippa S, Izzo C (1999) Ultrastructure of vegetative and sporulation stages of Haplosporidium ascidiarum from the ascidian Ciona intestinalis. Eur J Protistol 35: 175-182

Diggles BK, Nichol J, Hine PM, Wakefield S, CochennecLaureau N, Roberts RD, Friedman CS (2002) Pathology of cultured paua Haliotis iris infected with a novel haplosporidian parasite, with some observations on the cause of disease. Dis Aquat Org 50:219-231

Duboscq O, Harant H (1923) Sur les sporozoaires des tuniciers. CR Hebd Séances Acad Sci 177:432-434

Figueras A, Robledo JAF, Novoa B (1996) Brown ring disease and parasites in clams (Ruditapes decussatus and $R$. philippinarum) from Spain and Portugal. J Shellfish Res 15:363-368

Hine PM, Thorne T (2002) Haplosporidium sp. (Alveolata: Haplosporidia) associated with mortalities among rock oysters Saccostrea cucculata in NW Australia. Dis Aquat Org 51:123-133

Kawamura K, Nakauchi M (1986) Establishment of the island culture of the colonial ascidian Botrylloides simodensis. Mar Fouling 6:7-14

Lauzon RJ, Rinkevich B, Patton CW, Weissman IL (2000) A

Editorial responsibility: Albert Sparks,

Seattle, Washington, USA morphological study of non-random senescence in a colonial urochordate. Biol Bull 198:367-378

Levine ND (1981) New species of Lankesteria (Apicomplexa, Eugregarinida) from ascidians on the Central California Coast. J Protozool 28:363-370

Magor BG, De Tomaso A, Rinkevich B, Weissman IL (1999) Allorecognition in colonial tunicates: protection against predatory cell lineages? Immunol Rev 167:69-79

Monniot C (1990) Diseases of Urochordata. In: Kinne O (ed) Diseases of marine animals, Vol III. Biological Anstalt Helgoland, Hamburg, p 569-635

Mukai H, Watanabe H (1976) Studies on the formation of germ cells in a compound ascidian Botryllus primigenus Oka. J Morphol 148:337-362

Ormières MR (1965) Recherches sur les sporozoaries parasites des tuniciers. Vie Milieu 15:823-946

Ormières MR, De Puytorac M (1968) Ultrastructure des spores de l'haplosporidie Haplosporidium ascidiarum endoparasite du tunicier Sydnium elegans Giard. CR Hebd Séances Acad Sci 266:1134-1136

Perkins FO (1990) Phylum Haplosporidia. In: Margulis E, Corliss JO, Melkonian M, Chapman J (eds) Handbook of Protoctista. Johns \& Bartlett, Boston, MA, p 19-29

Perkins FO (1991) 'Sporozoa': Apicomplexa, Microsporidia, Haplosporidia, Paramyxea, Myxosporidia, and Actinosporidia. In: Harrison FW (ed) Anatomy of invertebrates, Vol 1, Protozoa. Wiley-Liss, New York, p 261-331

Rinkevich B (2002) The colonial urochordate Botryllus schlosseri: from stem cells and natural tissue transplantation to issues in evolutionary ecology. BioEssays 24:730-740

Rinkevich B, Rabinowitz C (1993) In vitro culture of blood cells from the colonial protochordate Botryllus schlosseri. In Vitro Cell Dev Biol 29A:79-85

Rinkevich B, Shapira M (1998) An improved diet for inland broodstock and the establishment of an inbred line from Botryllus schlosseri, a colonial sea squirt (Ascidiacea). Aquat Living Resour 11:163-171

Rinkevich B, Weissman IL (1987) A long-term study of fused subclones of a compound ascidian. The resorption phenomenon. J Zool 213:717-733

Submitted: February 8, 2003; Accepted: February 3, 2004 Proofs received from author(s): June 18, 2004 